\title{
Online evaluation of milk quality according to coagulation properties for its optimal distribution for industrial applications
}

\author{
G. Leitner, ${ }^{\star 1}$ Y. Lavi, † U. Merin,‡ L. Lemberskiy-Kuzin,§ and G. Katz§ \\ ${ }^{*}$ National Mastitis Reference Center, Kimron Veterinary Institute, Ministry of Agriculture and Rural Development, PO Box 12 , \\ Bet Dagan 50250, Israel \\ †Sha'ar Efraim 42835, Israel \\ ¥Department of Food Science, Agricultural Research Organization, the Volcani Center, PO Box 6, Bet Dagan 50250, Israel \\ §S.A.E. Afikim, Afikim 15148, Israel
}

\begin{abstract}
The potential for application of online devices for providing real-time analysis of milk-clotting parameters during milking was studied. The experiment tested established relationships between glandular-level bacterial infection and milk-clotting parameters as evaluated by visible or near-infrared spectroscopy. The parameters yielded by the AfiLab (S.A.E. Afikim, Afikim, Israel) online device were shown to be applicable to derivation of real-time estimations of milk-clotting parameters on the individual cow level. The ability of the AfiLab to perform this task was validated online and statistically by calibration against laboratory testing procedures.
\end{abstract}

Key words: online measurement, milk quality, milk clotting parameter

\section{INTRODUCTION}

Under prevailing practices milk delivered to dairy plants is graded upon reception, according to acceptable standards of hygienic quality. In most countries, these standards include upper limits on transportation temperature, bacterial counts, antibiotic residues, and SCC (McLaughlin, 2006; USFDA, 2007). The final price paid to the farmer is based on a combination of the hygienic quality and measured contents of milk constituents, namely, fat, protein, and lactose, which reflect its suitability for industrial production. It is well documented that the shelf-life of pasteurized milk depends on raw milk quality and that high SCC adversely affect milk composition, and cheese quality and yield (Munro et al., 1984; Politis and Ng-Kwai-Hang, 1988; Barbano et al., 1991; Klei et al., 1998; Leitner et al., 2006; Merin et al., 2008). However, recent findings have shown that SCC and storage time do not account for

Received October 19, 2010.

Accepted February 13, 2011.

${ }^{1}$ Corresponding author: leitnerg@moag.gov.il the variations in curd yield in such milk (Leitner et al., 2008).

Bulk tank milk (BTM) is a mixture of the contributions from many individual cows; therefore, all BTM have differing qualities. Regulations and agreements in diverse countries were framed to exclude unacceptable milk from the bulk, and elimination of such milk (i.e., that from animals infected with zoonoses, or milk with high SCC obtained from IMI glands, especially those with clinical mastitis), successfully improved milk quality. However, despite this improvement, milk with high SCC that comes from animals or glands with subclinical IMI and from animals at the end of their lactation (Leitner et al., 2011) can still enter the BTM, as long as the average SCC in the tank does not exceed the accepted levels. Such milk is distinguished especially by low levels of lactose, which causes impairment of its coagulation properties (i.e., longer rennet clotting time and lower curd firmness; Leitner et al., 2011). Imposition of regulations and controls to prevent milk from such animals from entering the BTM is almost impossible. Thus, predictive correlations of changes in milk composition caused by subclinical mastitis that worked reasonably well at the individual-cow levels (Leitner et al., 2006) lost much of their predictive value on the BTM level (Leitner et al., 2008).

In modern dairy farms, milking parlors are frequently equipped with computerized sensors that provide farmers with online measures of milk composition such as fat, protein, and lactose contents, SCC, and electrical conductivity.

Mid-infrared (IR; De Marchi et al., 2009; Soyeurt et al., 2010) and near-IR (NIR) spectroscopy (Tsenkova et al., 1999, 2006) are commonly used for low-cost analysis of milk components. However, to be effective in an uncontrolled environment such as the milking parlor, these techniques also should feature robustness. Measurements in mid-IR and far NIR are capable of storing more information than those in the visible to low-NIR range (350 to 1,000 $\mathrm{nm}$ ), because the former wavelength range is of lower energy, but they are more 
sensitive to environmental noise. Schmilovitch et al. (2000) have verified the ability to obtain accurate spectroscopic analyses of milk components by using the range below 1,000 $\mathrm{nm}$. Because of the greater robustness of measurements in this range, this technology was implemented in the AfiLab equipment (S.A.E. Afikim, Afikim, Israel), which is a near-IR online milk spectrometric analyzer (Katz et al., 2007). Currently, this equipment is installed in the milk pipe line in every stall in the milking parlor at the Volcani Center (Bet Dagan, Israel), and it provides real-time measurements of fat, protein, and lactose contents during the milking session.

The present study investigated the potential of the AfiLab equipment to provide real-time analysis of milkclotting parameters. The first part of the experimental study examined whether the previously established relationship between glandular-level bacterial infection and milk-clotting parameters could be evaluated by visible to NIR spectroscopy. Glandular-level milk samples were taken from individual cows and their spectroscopic parameters were analyzed in vitro. After positive responses had been obtained, the values of these parameters provided by the online AfiLab equipment were tested for applicability to real-time estimation of milk-clotting parameters on the individual-cow level.

\section{MATERIALS AND METHODS}

The first experiment (experiment 1) addressed the glandular level; the second (experiment 2) involved online cow-level analysis of milk-quality measures and milk-clotting parameters in the milking parlor.

\section{Study Layout of Experiment 1}

Thirty-one cows from the experimental herd of the Agricultural Research Organization (ARO; Bet Dagan, Israel) were selected for this study. The selected cows were infected in at least 1 quarter (gland) with 1 of the following bacteria, which are the most common found in Israeli herds: Escherichia coli, Streptococcus dysgalactiae, and CNS, mainly Staphylococcus chromogenes. In each cow, at least 1 quarter was uninfected and served as control. In addition, milk from cows in which all 4 glands were uninfected was sampled, and these samples served both as controls and as covariates to samples from cows in which at least 1 gland was infected. In experiment 1, on the day of testing, glands were sampled twice: for foremilk and total milk, whereas in experiment 2 , only total milk was sampled. After cleaning and disinfecting the teats, a 5-mL milk sample was taken for bacteriology, an additional 300$\mathrm{mL}$ sample was taken from each tested gland, and then the rest of the milk was taken with individual quartermilkers. At the end of milking, the milk of each quarter was gently blended and another 300-mL sample (i.e., total) was taken.

\section{Study Layout of Experiment 2}

Experiment 2 involved sampling milk from 423 cows in 2 farms; 159 cows in farm A and 264 in farm B. Cows were characterized according to their udder infection status (UIS): those with no bacterial finding (NBF) in all 4 glands were characterized as NBF; those infected in at least 1 gland with 1 of the above bacteria were characterized as infected. Cows were milked, and representative $300-\mathrm{mL}$ samples of the whole udder milk were collected.

\section{Analysis}

Bacterial identification and SCC were based on pretrial quarter foremilk samples, taken aseptically 2 or 3 times at 2-wk intervals during the morning milking, and tested at the laboratory within $1 \mathrm{~h}$ for bacteriology according to Oliver et al. (2004) and for SSC with a Coulter Z1 cell counter (Coulter Electronics, Luton, UK). Visible-NIR transmittance spectra of milk samples at $37^{\circ} \mathrm{C}$ were recorded with a USB2000 spectrometer (Ocean Optics, Dunedin, FL) with an optical path of 5 $\mathrm{mm}$ over the range of 350 to $1,000 \mathrm{~nm}$ in $0.4-\mathrm{nm}$ steps.

In both experiments, DIM, days in pregnancy (DIP), and milk quantity $(\mathrm{kg} / \mathrm{d})$, were recorded on the day of testing by the AfiMilk (S.A.E. Afikim) online data recording system. Milk gross composition, protein, casein, fat, lactose, and urea contents were analyzed with the Milkoscan 6000 (Foss Electric, Hillerød, Denmark), and SCC with a Fossomatic 360 (Foss Electric). Rennet clotting time (RCT; min) and curd firmness (CF; V) after 90 min (CF-90) were measured with the Optigraph instrument (Ysebaert, Frepillon, France) as described by Leitner et al. (2011).

A calibration model for extracting $\mathrm{RCT}$ and $\mathrm{CF}$ from the spectral data was based on partial least square (PLS) regression between the spectra and the corresponding Optigraph reference data. A genetic algorithm was used to determine the size and identity of the latent variables (Jouan-Rimbaud et al., 1995; Zeiri et al., 1995). Cross-validation was performed with a leave-one-out approach, in which the model is calibrated by using all data points but one, which is then used for prediction. This is repeated for all data points in turn, and the average errors are computed and used for evaluation. Leave-one-out cross-validation enables conclusions to be based on examination of a relatively small ensemble of data, because this technique is very 
intolerant of over-fitting. The calibration model for RCT and CF-90 that was developed from the spectral data was then implemented online in the AfiLab in the milking parlor during milking.

\section{Statistical Analysis}

Experiment 1. Correlations between the sampling results were determined with the udder used as the experimental unit. Comparisons were between sample values and total values of milk clotting parameters: RCT, CF-90, percentages of fat, protein, casein, (as percentage of total protein), and lactose, urea content, and SCC. Quarter infection status (NBF or infected) results were subjected to Student's $t$-test, using the total values of RCT and CF-90. Continuous variables (percentages of fat, protein, lactose, and percent casein, SCC, and urea content) were included in an ANOVA model in a random design, with infection status (NBF or infected) as fixed effects and continuous variables as co-variants. Interactions between infection status and the continuous variables were also included in the model.

Correlation between RCT and CF-90 values was determined for the NBF and infected groups separately.

The statistical model was

$$
\begin{gathered}
Y_{\mathrm{ijklmnop}}=\mu+\alpha_{\mathrm{i}}+\beta_{\mathrm{j}}+\gamma_{\mathrm{k}}+\delta_{\mathrm{l}}+\varepsilon_{\mathrm{m}}+\zeta_{\mathrm{n}}+\eta_{\mathrm{o}} \\
+\alpha \beta_{\mathrm{ij}}+\alpha \gamma_{\mathrm{ik}}+\alpha \delta_{\mathrm{il}}+\alpha \varepsilon_{\mathrm{im}}+\alpha \zeta_{\mathrm{in}}+\alpha \eta_{\mathrm{io}}+\mathrm{e}_{\mathrm{ijklmnop}},
\end{gathered}
$$

where $\mu$ is the grand mean; $\alpha_{i}$ represents the fixed effect of the UIS; $\beta_{\mathrm{j}}$ represents the covariance of percentage of fat; $\gamma_{\mathrm{k}}$ represents the covariance of percentage protein; $\delta_{1}$ represents the covariance of percentage of lactose; $\varepsilon_{\mathrm{m}}$ represents the covariance of percentage of casein; $\zeta_{\mathrm{n}}$ represents the covariance of SCC; $\eta_{\mathrm{o}}$ represents the covariance of urea concentration; $\alpha \beta_{\mathrm{ij}}$ represents the UIS $\times$ percentage of fat interaction; $\alpha \gamma_{\mathrm{ik}}$ represents the UIS $\times$ percentage of protein interaction; $\alpha \delta_{i 1}$ represents the UIS $\times$ percentage of lactose interaction; $\alpha \varepsilon_{\text {im }}$ represents the UIS $\times$ percentage of casein interaction; $\alpha \zeta_{\text {in }}$ represents the UIS $\times$ SCC interaction; $\alpha \eta_{\text {io }}$ represents the UIS $\times$ urea interaction; and $\mathrm{e}_{\mathrm{ijk} k \mathrm{mnop}}=$ residual variance between measurements (random error).

Experiment 2. The correlations between the UIS (NBF or infected) and the analyzed parameters, and between the infecting bacterial group $(1,2,3$, or 4$)$ and the analyzed parameters were subjected to the Tukey-Kramer Highest Significant Difference (HSD) $t$ test. The continuous variables that affect the analyzed parameters (RCT or CF-90) were subjected to stepwise regression (probability to enter $=0.20$ ); they included: percentages of fat, protein, and lactose, SCC, urea,
DIM, DIP, and milk quantity. The selected sources (continuous variables) were included in 2 different ANOVA models:

- An ANOVA model in a block design (i.e., farm) used UIS (NBF or infected), lactation number (1, 2 , or more), and the interaction between them as fixed effects, and the selected sources as covariables. Interactions between the UIS and the continuous variables were also included in the model. In a similar ANOVA model, interactions between the bacterial infection group and the continuous variables were also included, and were subjected to multiple comparisons by the TukeyKramer HSD $t$-test.

The model analyzing the parameter RCT was

$$
\begin{gathered}
Y_{\mathrm{ijklmnopq}}=\mu+\mathrm{B}_{\mathrm{i}}+\alpha_{\mathrm{j}}+\gamma_{\mathrm{k}}+\alpha \gamma_{\mathrm{jk}}+\delta_{\mathrm{l}}+\varepsilon_{\mathrm{m}}+\zeta_{\mathrm{n}} \\
+\eta_{\mathrm{o}}+\theta_{\mathrm{p}}+\alpha \delta_{\mathrm{jl}}+\alpha \varepsilon_{\mathrm{jm}}+\alpha \zeta_{\mathrm{jn}}+\alpha \eta_{\mathrm{jo}} \\
+\alpha \theta_{\mathrm{jp}}+\mathrm{e}_{\mathrm{ijklmnopq}}
\end{gathered}
$$

where $\mu$ is the grand mean; $B_{i}$ represents the variance between farms; $\alpha_{j}$ represents the fixed effect of the UIS; $\gamma_{\mathrm{k}}$ represents the fixed effect of lactation; $\alpha \gamma_{\mathrm{jk}}$ represents the UIS $\times$ lactation interaction; $\delta_{1}$ represents the covariance of percentage of lactose; $\varepsilon_{\mathrm{m}}$ represents the covariance of SCC; $\zeta_{n}$ represents the covariance percentage of protein; $\eta_{0}$ represents the covariance of urea concentration; $\theta_{\mathrm{p}}$ represents the covariance of percentage of fat; $\alpha \delta_{j 1}$ represents the UIS $\times$ percentage of lactose interaction; $\alpha \varepsilon_{j m}$ represents the UIS $\times$ SCC interaction; $\alpha \zeta_{\text {jn }}$ represents the UIS $\times$ percentage of protein interaction; $\alpha \eta_{\mathrm{jo}}$ represents the UIS $\times$ urea interaction; $\alpha \theta_{\mathrm{jp}}$ represents the UIS $\times$ percentage of fat interaction; and $\mathrm{e}_{\mathrm{ijklmnopq}}=$ residual variance between measurements (random error).

The model analyzing the parameter CF-90 was

$$
\begin{gathered}
Y_{\mathrm{ijklmnopqrst}}=\mu+\mathrm{B}_{\mathrm{i}}+\alpha_{\mathrm{j}}+\gamma_{\mathrm{k}}+\alpha \gamma_{\mathrm{jk}}+\delta_{\mathrm{l}}+\varepsilon_{\mathrm{m}} \\
+\zeta_{\mathrm{n}}+\eta_{\mathrm{o}}+\theta_{\mathrm{p}}+\kappa_{\mathrm{q}}+\lambda_{\mathrm{r}}+\pi_{\mathrm{s}}+\alpha \delta_{\mathrm{jl}}+\alpha \varepsilon_{\mathrm{jm}}+\alpha \zeta_{\mathrm{jn}} \\
+\alpha \eta_{\mathrm{jo}}+\alpha \theta_{\mathrm{jp}}+\alpha \kappa_{\mathrm{jq}}+\alpha \lambda_{\mathrm{jr}}+\alpha \pi_{\mathrm{js}}+\mathrm{e}_{\mathrm{ijklmnopqrst}},
\end{gathered}
$$

where $\mu$ is the grand mean; $B_{i}$ represents the variance between farms; $\alpha_{j}$ represents the fixed effect of the UIS; $\gamma_{\mathrm{k}}$ represents the fixed effect of lactation; $\alpha \gamma_{\mathrm{jk}}$ represents the UIS $\times$ lactation interaction; $\delta_{1}$ represents the covariance of percentage of protein; $\varepsilon_{\mathrm{m}}$ represents the covariance of SCC; $\zeta_{n}$ represents the covariance percentage of fat; $\eta_{\mathrm{o}}$ represents the covariance of DIP; $\theta_{\mathrm{p}}$ represents the covariance of percentage of lactose; 
$\kappa_{\mathrm{q}}$ represents the covariance of DIM; $\lambda_{\mathrm{r}}$ represents the covariance of urea concentration; $\pi_{\mathrm{s}}$ represents the covariance of milk; $\alpha \delta_{j 1}$ represents the UIS $\times$ percentage of protein interaction; $\alpha \varepsilon_{\mathrm{jm}}$ represents the UIS $\times \mathrm{SCC}$ interaction; $\alpha \zeta_{\text {jn }}$ represents the UIS $\times$ percentage of fat interaction; $\alpha \eta_{\mathrm{jo}}$ represents the UIS $\times$ DIP interaction; $\alpha \theta_{\mathrm{jp}}$ represents the UIS $\times$ percentage of lactose interaction; $\alpha \kappa_{\mathrm{jq}}$ represents the UIS $\times$ DIM interaction; $\alpha \lambda_{\mathrm{jr}}$ represents the UIS $\times$ urea interaction; $\alpha \pi_{\mathrm{js}}$ represents the UIS $\times$ milk interaction; and $\mathrm{e}_{\mathrm{ijklmnopqrst}}=$ residual variance between measurements (random error).

- The NBF cows were analyzed separately, and the change in CF-90 throughout the pregnancy (DIP) was determined by regression. The continuous variables that affect CF-90 of NBF cows were screened by stepwise regression (probability to enter $=0.20$ ); they included: percentages of fat, protein, and lactose, SCC, urea, DIM, DIP, and milk quantity. The selected sources (continuous variables) were included in an ANOVA model in a block design (i.e., farm) using lactation (first or second and up) as fixed effect and the continuous variables as co-variables (SAS institute, 2000).

The model analyzing the parameter RCT was

$$
\begin{aligned}
Y_{\mathrm{ijklmnopq}}=\mu & +\mathrm{B}_{\mathrm{i}}+\alpha_{\mathrm{j}}+\gamma_{\mathrm{k}}+\alpha \gamma_{\mathrm{jk}}+\delta_{\mathrm{l}}+\varepsilon_{\mathrm{m}}+\zeta_{\mathrm{n}} \\
+ & \eta_{\mathrm{o}}+\theta_{\mathrm{p}}+\alpha \delta_{\mathrm{jl}}+\alpha \varepsilon_{\mathrm{jm}}+\alpha \zeta_{\mathrm{jn}} \\
& +\alpha \eta_{\mathrm{jo}}+\alpha \theta_{\mathrm{jp}}+\mathrm{e}_{\mathrm{ijklmnopq}},
\end{aligned}
$$

where $\mu$ is the grand mean; $B_{i}$ represents the variance between farms; $\alpha_{j}$ represents the fixed effect of the infection bacterial group (IBG); $\gamma_{\mathrm{k}}$ represents the fixed effect of lactation; $\alpha \gamma_{\mathrm{jk}}$ represents the IBG $\times$ lactation interaction; $\delta_{1}$ represents the covariance of percentage of lactose; $\varepsilon_{\mathrm{m}}$ represents the covariance of SCC; $\zeta_{\mathrm{n}}$ represents the covariance percentage of protein; $\eta_{\mathrm{o}}$ represents the covariance of urea concentration; $\theta_{\mathrm{p}}$ represents the covariance of percentage of fat; $\alpha \delta_{j 1}$ represents the IBG $\times$ percentage of lactose interaction; $\alpha \varepsilon_{j m}$ represents the $\mathrm{IBG} \times \mathrm{SCC}$ interaction; $\alpha \zeta_{\text {jn }}$ represents the IBG $\times$ percentage of protein interaction; $\alpha \eta_{\mathrm{jo}}$ represents the IBG $\times$ urea interaction; $\alpha \theta_{\text {jp }}$ represents the IBG $\times$ percentage of fat interaction; and $\mathrm{e}_{\mathrm{ijk} k \mathrm{mnopq}}=$ residual variance between measurements (random error).

The model analyzing the parameter CF-90 was

$$
\begin{gathered}
Y_{\mathrm{ijklmnopqrst}}=\mu+\mathrm{B}_{\mathrm{i}}+\alpha_{\mathrm{j}}+\gamma_{\mathrm{k}}+\alpha \gamma_{\mathrm{jk}}+\delta_{\mathrm{l}}+\varepsilon_{\mathrm{m}} \\
+\zeta_{\mathrm{n}}+\eta_{\mathrm{o}}+\theta_{\mathrm{p}}+\kappa_{\mathrm{q}}+\lambda_{\mathrm{r}}+\pi_{\mathrm{s}}+\alpha \delta_{\mathrm{jl}}+\alpha \varepsilon_{\mathrm{jm}}+\alpha \zeta_{\mathrm{jn}} \\
+\alpha \eta_{\mathrm{jo}}+\alpha \theta_{\mathrm{jp}}+\alpha \kappa_{\mathrm{jq}}+\alpha \lambda_{\mathrm{jr}}+\alpha \pi_{\mathrm{js}}+\mathrm{e}_{\mathrm{ijklmnopqrst}},
\end{gathered}
$$

where $\mu$ is the grand mean; $B_{i}$ represents the variance between farms; $\alpha_{j}$ represents the fixed effect of the IBG; $\gamma_{\mathrm{k}}$ represents the fixed effect of lactation; $\alpha \gamma_{\mathrm{jk}}$ represents the IBG $\times$ lactation interaction; $\delta_{1}$ represents the covariance of percentage of protein; $\varepsilon_{\mathrm{m}}$ represents the covariance of SCC; $\zeta_{n}$ represents the covariance percentage of fat; $\eta_{\mathrm{o}}$ represents the covariance of DIP; $\theta_{\mathrm{p}}$ represents the covariance of percentage of lactose; $\kappa_{\mathrm{q}}$ represents the covariance of DIM; $\lambda_{\mathrm{r}}$ represents the covariance of urea concentration; $\pi_{\mathrm{s}}$ represents the covariance of milk; $\alpha \delta_{\mathrm{jl}}$ represents the IBG $\times$ percentage of protein interaction; $\alpha \varepsilon_{\mathrm{jm}}$ represents the IBG $\times \mathrm{SCC}$ interaction; $\alpha \zeta_{\mathrm{jn}}$ represents the IBG $\times$ percentage of fat interaction; $\alpha \eta_{\mathrm{jo}}$ represents the IBG $\times$ DIP interaction; $\alpha \theta_{\text {jp }}$ represents the IBG $\times$ percentage of lactose interaction; $\alpha \kappa_{\mathrm{jq}}$ represents the IBG $\times$ DIM interaction; $\alpha \lambda_{\mathrm{jr}}$ represents the IBG $\times$ urea interaction; $\alpha \pi_{\mathrm{js}}$ represents the IBG $\times$ milk interaction; and $\mathrm{e}_{\mathrm{ijk} k \mathrm{mnopqrst}}=$ residual variance between measurements (random error).

\section{RESULTS}

\section{Experiment 1}

Sampling Procedure. The correlations between the measured values of the milk-quality parameters for foremilk and total, for all infected and uninfected glands are presented in Table 1 . The variables were divided among 3 major groups according to the correlation coefficient $(r)$ : high correlation $(r>0.9)$ for percentages of protein and casein, and SCC; intermediate correlation $(0.8<\mathrm{r}<0.9)$ for RCT, CF-90, and urea concentration; and low correlation $(\mathrm{r}<0.8)$ for percentages of fat and lactose. The low correlations obtained for fat were due to the increase of fat percentage from low to high during milking, which influenced its intermediate correlation with RCT and CF-90. However, the high correlations of casein (the coagulating protein) and SCC (the indicator of udder health) with the milk-clotting parameters RCT and CF-90 indicate that both milk sampling procedures, at the beginning of the milking (foremilk) and at the end of the milking (total) were reliable for evaluating these parameters.

Main Factors Affecting RCT and CF. The effects of quarter infection status (NBF or infected) on the total values for RCT and for CF-90 are compared in Figures $1 \mathrm{~A}$ and $1 \mathrm{~B}$, respectively. The infected group had significantly $(P<0.001)$ higher RCT values $(2,407$ and $1,029 \mathrm{~s}$, respectively) and significantly $(P<0.001)$ lower $\mathrm{CF}-90$ values (6.88 and $11.25 \mathrm{~V}$, respectively) than did the NBF group.

Of the 57 glands tested, 33 glands were categorized as NBF and 21 were infected with E. coli (8), Strep. dysgalactiae (6), or CNS (7). The values of RCT and 
Table 1. Correlations between foremilk and total milk values for rennet clotting time (RCT), curd firmness after 90 min (CF-90), percentages of fat, protein, lactose, and casein, SCC, and urea concentration for 57 quarters [33 no bacterial finding (NBF) and 21 infected with various bacteria]

\begin{tabular}{lcc}
\hline $\begin{array}{l}\text { Variable } \\
\text { (foremilk vs. total) }\end{array}$ & $\mathrm{r}$ & $P$-value \\
\hline RCT (s) & 0.847 & $<0.0001$ \\
CF-90 (V) & 0.812 & $<0.0001$ \\
Fat (\%) & 0.701 & $<0.0001$ \\
Protein (\%) & 0.951 & $<0.0001$ \\
Lactose (\%) & 0.636 & $<0.0001$ \\
Casein (\%) & 0.925 & $<0.0001$ \\
SCC & 0.959 & $<0.0001$ \\
Urea (\%) & 0.873 & $<0.0001$ \\
\hline
\end{tabular}

CF-90, as associated with the various bacterial infection groups, are presented in Table 2 . No differences in RCT and CF-90 values were found between uninfected glands and those infected with CNS, whereas both Strep. dysgalactiae and E. coli significantly increased RCT and decreased CF-90 (Table 2).

The ANOVA model that is presented in Table 3 included effects on the RCT and CF-90 values of 7 main milk-quality parameters: UIS, percentages of fat, protein, lactose, and casein, SCC, and urea concentration. No significant interactions were found between UIS and any of the other tested parameters in their effects on RCT. Effects of protein percentage on RCT were significant and similar in NBF and infected milk: a $1 \%$ increase in protein increased RCT by 2,794 units. Effects of lactose percentage were significant and similar in NBF and infected milk: a $1 \%$ decrease in lactose increased RCT by 769 units; the model accounted for $88 \%$ of the variance in RCT as measured in total milk. A significant $(P=0.0056)$ difference was observed between the CF-90 values in the respective UIS groups,
Table 2. Effect of bacterial type on rennet clotting time (RCT) and curd firmness after 90 min (CF-90) of 33 no bacterial finding (NBF) glands and 21 infected glands according to the various bacteria (mean $\pm \mathrm{SD})$

\begin{tabular}{lcrc}
\hline $\begin{array}{l}\text { Bacteria } \\
\text { group }\end{array}$ & Number & CF-90 & RCT \\
\hline NBF & 33 & $11.25 \pm 0.07^{\mathrm{a}}$ & $1,029 \pm 392^{\mathrm{b}}$ \\
CNS & 7 & $10.10 \pm 0.57^{\mathrm{a}}$ & $1,235 \pm 173^{\mathrm{b}}$ \\
Streptococcus dysgalactiae & 6 & $4.95 \pm 1.63^{\mathrm{b}}$ & $2,713 \pm 429^{\mathrm{a}}$ \\
Escherichia coli & 8 & $5.52 \pm 1.20^{\mathrm{b}}$ & $2,295 \pm 515^{\mathrm{a}}$ \\
\hline
\end{tabular}

a,b Parameters within row with no common superscript differ significantly $(P<0.05)$.

and it was significantly $(P=0.0069)$ affected by SCC: a 1-unit increase in SCC decreased CF-90 by 0.02 units in the infected group but did not affect it in the NBF group. No significant interactions were found between UIS and effects of other tested variables on CF-90. Fat and casein percentages each had similar significant effects on CF-90 in both NBF and infected groups (i.e., no significant interactions): $1 \%$ increases in fat and in casein increased CF-90 by 1.39 and 22.35 units, respectively. The model accounted for $78 \%$ of the variance between CF-90 values as measured in total milk.

The correlations between RCT and $\mathrm{CF}-90$ values are presented in Figure 2 for NBF and infected groups separately. No correlation between RCT and CF-90 was found in NBF glands, but in infected glands, a significant negative correlation between the 2 variables was found: an increase of 1,000 $\mathrm{s}$ in RCT corresponded to a 2.819-unit decrease in CF-90 (data not shown).

Calibration of Milk Transmittance VisibleNIR Spectra. The correlations between the clotting parameters RCT and CF-90 and the measurements of the 57 foremilk and total milk samples were calibrated and validated with the SB2000 spectrometer. No sig-
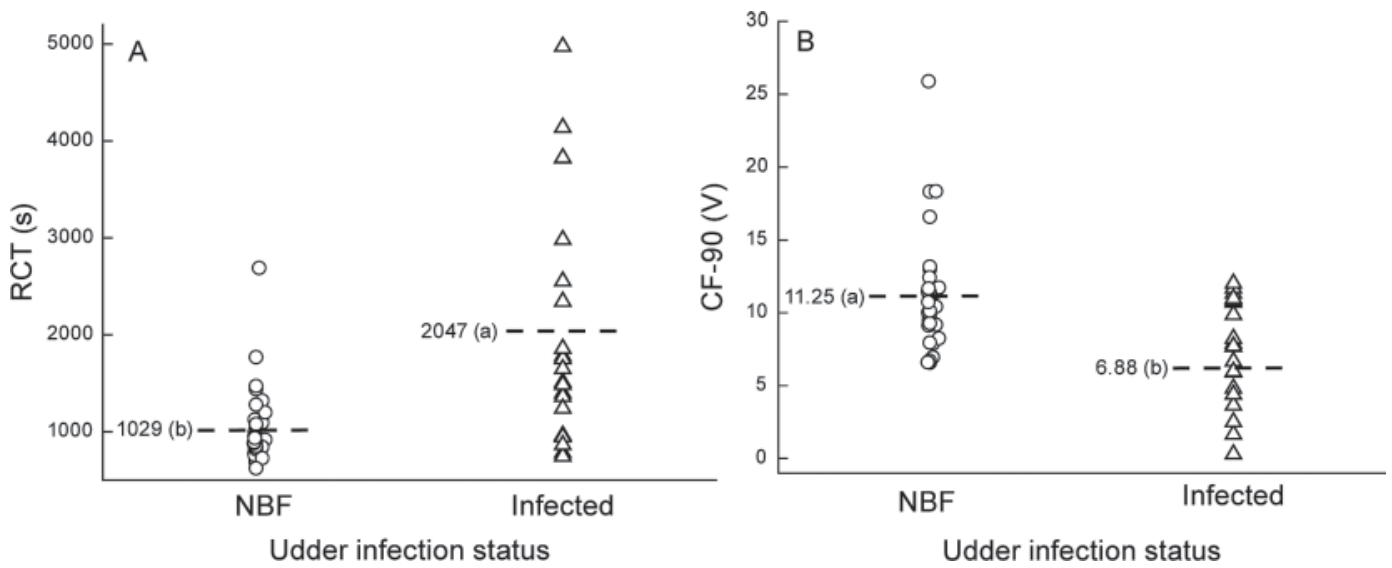

Figure 1. Rennet clotting time (RCT; A) and curd firmness after 90 min (CF-90; B) distribution and means (dashed lines) in 33 no bacterial finding $(\mathrm{NBF})$ glands and 21 infected glands. ${ }^{\mathrm{a}, \mathrm{b}}$ Within each panel, values followed by different letters in parentheses differ significantly $(P$ $<0.05)$. 


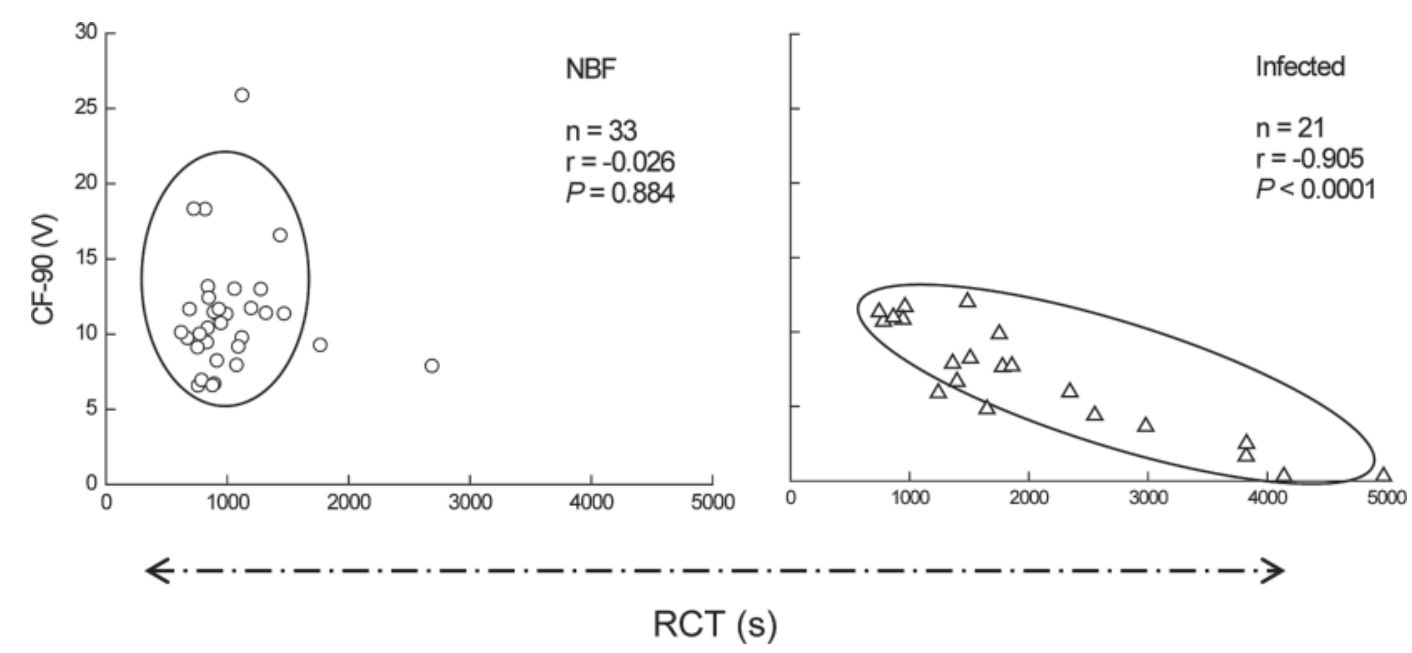

Figure 2. Correlation between rennet clotting time (RCT) and curd firmness after 90 min (CF-90) in no bacterial finding (NBF; left) and infected (right) glands.

nificant differences were found between foremilk and total milk results (data not shown); therefore, only the foremilk results are summarized in Table 4. Based on the calibration, predicted values for AfiLab measurements, and RCT and CF-90 values as measured by the Optigraph are summarized in Figure 3.

\section{Experiment 2}

Categorization of Cows. Of the 423 cows tested, 258 were categorized as NBF and 165 as infected in at least 1 gland with E. coli (29), Strep. dysgalactiae (12), or CNS (124). Table 5 summarizes the means and SE of lactation, DIM, DIP, SCC, milk (kg/d), percentages of fat, protein, and lactose, and urea content, as related to UIS and infecting bacterium. The SCC was greater in all infected animals than in NBF ones, but the dif- ference was significant with respect to only $E$. coli and Strep. dysgalactiae.

The RCT and CF-90 values of the bacterial infection groups are presented in Figures 4 and 5, respectively. The infected group had significantly $(P=0.0119)$ higher RCT values than the NBF group (1,161 and 1,057 s, respectively), which can be related to infection with $E$. coli and some of the Strep. dysgalactiae (Figure 5). The infected and the NBF groups did not differ significantly in CF-90 (10.89 and $11.35 \mathrm{~V}$, respectively), whereas $E$. coli-infected glands (group 4) had significantly lower CF-90 than did groups 1, 2, or 3.

Screening of the Continuous Variables. Eight continuous variables (percentages of fat, protein, and lactose, SCC, urea concentration, DIM, DIP, and milk quantity) were subjected to stepwise regression to evaluate their effects on RCT and CF-90 (Table 6).
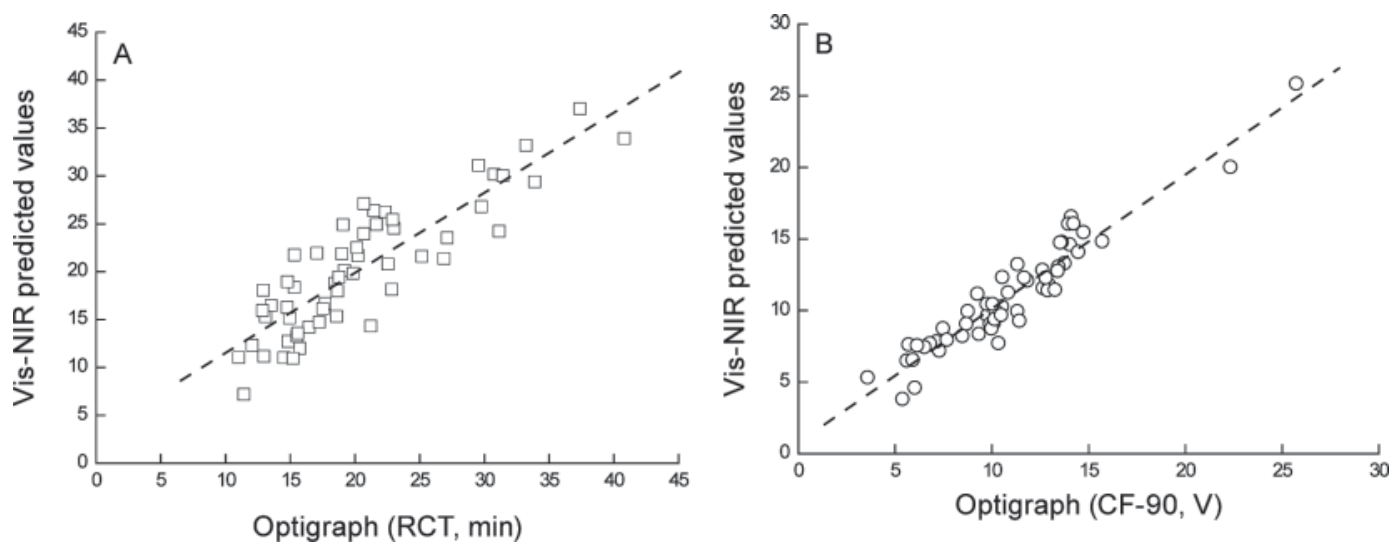

Figure 3. Correlations between values for rennet clotting time (RCT; A) and curd firmness after 90 min (CF-90; B) obtained by visible-nearinfrared (Vis-NIR) spectroscopy prediction and Optigraph (Ysebaert, Frepillon, France) measurements. 
Table 3. The ANOVA significance levels ( $P$-value) of the main effects and the interactions between effects on rennet clotting time (RCT) and curd firmness after $90 \mathrm{~min}(\mathrm{CF}-90)$

\begin{tabular}{lcc}
\hline Source & $\begin{array}{c}P \text {-value } \\
(\mathrm{RCT})\end{array}$ & $\begin{array}{c}P \text {-value } \\
(\mathrm{CF}-90)\end{array}$ \\
\hline Udder infection status (UIS) & 0.1211 & 0.0056 \\
Fat (\%) & 0.1830 & 0.0245 \\
Protein (\%) & 0.0469 & 0.0564 \\
Lactose (\%) & 0.0375 & 0.9999 \\
Casein (\%) & 0.1139 & 0.0345 \\
SCC & 0.0819 & 0.0042 \\
Urea (\%) & 0.7059 & 0.5502 \\
$\mathrm{n}$ & 54 & 54 \\
$\mathrm{R}^{2}$ & 0.88 & 0.78 \\
\hline
\end{tabular}

The stepwise regression identified 5 parameters that might affect RCT, and found that all 8 parameters might affect CF-90.

The ANOVA model comparison between the NBF and infected groups found 7 main variables that affected RCT values and 10 that affected CF-90 values; they are presented in Table 7 . Those that affected RCT were UIS, lactation, percentages of fat, protein, and lactose, SCC, and urea concentration; those that affected CF-90 were UIS, lactation, protein percentage, SCC, fat percentage, DIP, lactose percentage, DIM, urea concentration, and milk quantity.

For RCT values, significant $(P=0.0045)$ variance occurred between the farms, which represented $4.3 \%$ of the total variance in this trial. A significant effect was found for lactose, but it differed between the NBF and the infected groups (i.e., significant interaction; $P$ $=0.0203):$ a $1 \%$ increase in lactose decreased RCT by 598 and 220 units in the infected and NBF groups, respectively. The effects of SCC differed between the NBF and the infected groups, the interaction being significant at $P<0.0001$ : a 1 -unit increase in SCC caused RCT to increase by 0.3 units in the infected group and to decrease by 0.04 units in the NBF group. The effects of urea differed between the NBF and the infected groups, the interaction being significant at $P$ $=0.0301$ : a 0.01-unit increase in urea concentration decreased RCT by 103.05 and 21.17 units in the infected and NBF groups, respectively. The effects of protein and fat were similar in the 2 UIS groups.

For CF-90 values, significant $(P<0.0001)$ variance occurred between the farms, which represented $11.2 \%$ of the total variance in this trial. The 2 UIS groups exhibited significant similar effects (i.e., interactions were not significant) of several variables on CF-90: a $1 \%$ increase in protein caused a 3.04-unit increase; a 1,000-unit increase in SCC decreased CF-90 by 0.86 unit; a $1 \%$ increase in fat increased CF-90 by 0.87 unit; a 1-d increase in DIP increased CF-90 by 0.005 unit; a $1 \%$ increase in lactose increased CF-90 by 2.03 units;
Table 4. Calibration and validation statistics for determination of clotting parameters in raw milk by SB2000 spectrometer and Optigraph

\begin{tabular}{lccccc}
\hline Parameter & SEC & $\mathrm{R}$ & SECEV & $\mathrm{CV}_{\mathrm{r}}$ & $\begin{array}{c}\mathrm{CV} \\
(\%)\end{array}$ \\
\hline CF-90 & 1.03 & 97.5 & 1.228 & 94.9 & 11.27 \\
RCT & 150 & 94.6 & 208 & 86.7 & 17.06 \\
\hline
\end{tabular}

${ }^{1} \mathrm{SEC}=$ standard error of calibration; $\mathrm{R}=$ coefficient of multiple correlation; $\mathrm{SECEV}=$ standard error of cross-validation; $\mathrm{CV}_{\mathrm{r}}=$ crossvalidation correlation coefficient; $\mathrm{CV}=\mathrm{SECEV} /$ mean value; $\mathrm{CF}-90=$ curd firmness after $90 \mathrm{~min}$; RCT $=$ rennet clotting time. SB2000 spectrometer from Ocean Optics, Dunedin, FL; Optigraph from Ysebaert, Frepillon, France.

a 1-d increase in DIM increased CF-90 by 0.006 unit; and a 1-unit increase in urea concentration increased CF-90 by 40.3 units. The effects of milk quantity on CF-90 values were significant and differed between the $\mathrm{NBF}$ and the infected groups, the interaction being significant at $P=0.0302$ : a $1-\mathrm{kg}$ increase in milk quantity increased CF-90 by 0.091 and by only 0.001 unit in the infected and NBF groups, respectively.

The ANOVA model of the effects of bacterial infection groups is presented in Table 8 . The effects of protein and SCC on RCT values differed between the bacterial infection groups, the interactions being significant at $P$ $=0.0057$ and $P=0.0065$, respectively. The effects of lactose were the same in all 4 bacterial infection groups: a $1 \%$ increase in lactose decreased RCT by 507 units.

Effects of several continuous variables on CF-90 were significant and were similar among the bacterial infection groups: a $1 \%$ increase in protein increased CF-90 by 6.61 units; a $1 \%$ decrease in lactose decreased CF-90 by 5.09 units; a 1-d increase in DIP increased CF-90

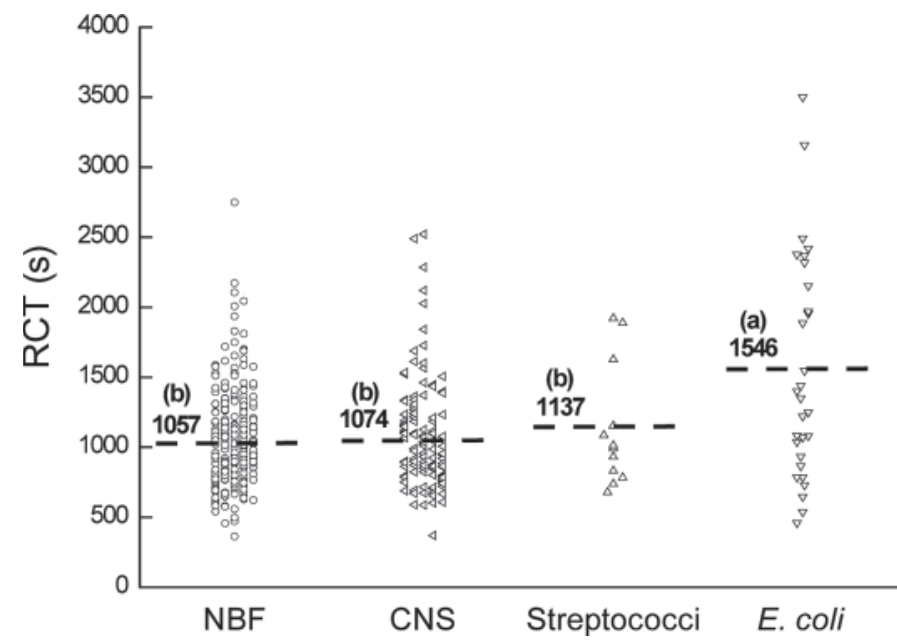

Figure 4. Distribution of rennet clotting time (RCT) in 4 udder infection bacteria groups [no bacterial finding (NBF), 258; CNS, 124; streptococci, 12; Escherichia coli, 29]. ${ }^{\mathrm{a}, \mathrm{b}}$ Values marked with different letters in parentheses differ significantly $(P<0.05)$. 
Table 5. Lactation number, DIM, days in pregnancy (DIP), SCC, milk yield, and concentrations of fat, protein, lactose, and urea in tested cows according to udder bacterial infection (mean $\pm \mathrm{SE}$ )

\begin{tabular}{lccccc}
\hline Parameter & $\begin{array}{c}\mathrm{NBF}^{1} \\
(\mathrm{n}=258)\end{array}$ & $\begin{array}{c}\text { Infected } \\
(\mathrm{n}=165)\end{array}$ & $\begin{array}{c}\text { Escherichia } \\
\text { coli }(\mathrm{n}=29)\end{array}$ & $\begin{array}{c}\text { Streptococcus } \\
\text { dysgalactiae }(\mathrm{n}=12)\end{array}$ & $\begin{array}{c}\text { CNS } \\
(\mathrm{n}=124)\end{array}$ \\
\hline Lactation & $2.63 \pm 0.1$ & $2.48 \pm 0.1$ & $3.39 \pm 0.3$ & $2.84 \pm 0.5$ & $2.24 \pm 0.1$ \\
DIM & $180 \pm 11.3$ & $212 \pm 10.8$ & $203 \pm 24.4$ & $250 \pm 58.2$ & $210 \pm 12.1$ \\
DIP & $50 \pm 4.1$ & $59 \pm 5.5$ & $59 \pm 12.6$ & $65 \pm 23.2$ & $58 \pm 6.3$ \\
SCC $\left(\times 10^{3}\right)$ & $107 \pm 28^{\mathrm{c}}$ & $319 \pm 77^{\mathrm{b}}$ & $952 \pm 425^{\mathrm{a}}$ & $405 \pm 122^{\mathrm{ab}}$ & $177 \pm 27^{\mathrm{bc}}$ \\
Milk (kg/d) & $36.5 \pm 0.6$ & $33.8 \pm 0.7$ & $35.5 \pm 2.3$ & $30.9 \pm 3.1$ & $33.7 \pm 0.7$ \\
Fat (\%) & $3.5 \pm 0.04$ & $3.6 \pm 0.05$ & $3.3 \pm 0.14$ & $3.6 \pm 0.35$ & $3.7 \pm 0.06$ \\
Protein (\%) & $3.4 \pm 0.03$ & $3.4 \pm 0.03$ & $3.2 \pm 0.07$ & $3.5 \pm 0.15$ & $3.4 \pm 0.04$ \\
Lactose (\%) & $5.0 \pm 0.01$ & $4.9 \pm 0.02$ & $4.7 \pm 0.06$ & $4.8 \pm 0.09$ & $4.9 \pm 0.02$ \\
Urea (\%) & $0.037 \pm<0.0$ & $0.036 \pm<0.0$ & $0.032 \pm<0.0$ & $0.039 \pm<0.0$ & $0.036 \pm<0.0$ \\
\hline
\end{tabular}

${ }^{a-c}$ Parameters within a row with no common superscript differ significantly $(P<0.05)$.

${ }^{1}$ No bacterial finding.

by 0.04 unit; a 1-d increase in DIM increased CF-90 by 0.01 unit; and a 1-kg increase in milk quantity increased CF-90 by 0.40 unit.

Online validation statistics for determination of clotting parameters in raw milk by the AfiLab are summarized in Table 9. The values predicted for $\mathrm{RCT}$ and $\mathrm{CF}$ 90 , and their values as measured with the Optigraph are summarized in Figure 6.

\section{DISCUSSION}

Our group has extensively studied the associations between various bacterial IMI, stage of lactation, and decreases in milk yield and quality (Leitner et al., 2006, 2008; Merin et al., 2008). These studies focused on milk-clotting parameters (i.e., RCT, CF, and curd yield), and demonstrated that for cheese and yogurt, these features had higher correlations than SCC or milk casein content with IMI. Tracking milk quality on the BTM level is currently impossible. However, one potential solution to this problem lies in online monitoring of changes in milk quality during milking, on the individual-cow level. This would enable distribution of milk according to its most appropriate use.
The implementation of new equipment, such as the AfiLab, for online recording of milk composition by use of near-IR, enabled us to perform a real-time experiment to validate the results by comparison with those obtained in the laboratory on the individual cow singlegland level.

Milk is one of the most complex natural suspensions. Stage of lactation, nutrition, stress and disease, and, in particular, IMI cause changes in milk composition that directly influence milk products (Auldist et al., 1996; Leitner et al., 2006; Merin et al., 2008). Most studies on milk quality correlated 1 parameter, such as SCC (Barbano et al., 1991; Auldist and Hubble, 1998), proteins, or casein (Urech et al., 1999) with yields of milk products such as cheese (Rogers and Mitchell, 1994). Moreover, the source of the studied milk was BTM, which is a mixture of the contributions of all of the individual cows milked into it. In a previous study, it was shown that various BTM that showed no significant differences in SCC $\left(150\right.$ to $350 \times 10^{3}$ cells $\left./ \mathrm{mL}\right)$, fat, protein and casein differed significantly in cheese yield (Leitner et al., 2008).

Thus, to ensure that low-quality milk does not enter the bulk tank, methods should be considered to

Table 6. Stepwise regression that might affect the values [5 parameters for rennet clotting time (RCT) values and all 8 parameters for curd firmness after $90 \mathrm{~min}$ (CF-90 values)]

\begin{tabular}{|c|c|c|c|c|c|c|}
\hline \multirow[b]{2}{*}{ Parameter } & \multicolumn{3}{|c|}{$\mathrm{RCT}$ value } & \multicolumn{3}{|c|}{ CF-90 value } \\
\hline & Step & $\begin{array}{l}\text { Significant } \\
\text { probability }\end{array}$ & $\mathrm{R}^{2}$ & Step & $\begin{array}{l}\text { Significant } \\
\text { probability }\end{array}$ & $\mathrm{R}^{2}$ \\
\hline Protein (\%) & 3 & 0.0002 & 0.145 & 1 & 0.0000 & 0.278 \\
\hline $\mathrm{SCC}(\times 1,000)$ & 2 & 0.0000 & 0.114 & 2 & 0.0000 & 0.320 \\
\hline Fat $(\%)$ & 5 & 0.0783 & 0.171 & 3 & 0.0000 & 0.348 \\
\hline Days in pregnancy & & & & 4 & 0.0014 & 0.364 \\
\hline Lactose $(\%)$ & 1 & 0.0000 & 0.070 & 5 & 0.0015 & 0.379 \\
\hline DIM & & & & 6 & 0.0286 & 0.387 \\
\hline Urea (\%) & 4 & 0.0018 & 0.165 & 7 & 0.0082 & 0.397 \\
\hline Milk (kg) & & 0.0002 & & 8 & 0.0494 & 0.403 \\
\hline
\end{tabular}


Table 7. The ANOVA significance levels ( $P$-values) of the main effect and the interactions between effects of udder infection status (UIS) groups [no bacterial finding (NBF) and infected] on rennet clotting time (RCT) and curd firmness after 90 min (CF-90 values)

\begin{tabular}{lcr}
\hline Source & $\begin{array}{c}P \text {-value } \\
(\mathrm{RCT})\end{array}$ & $\begin{array}{r}P \text {-value } \\
(\text { CF-90 })\end{array}$ \\
\hline Farm (random) & 0.0045 & $<0.0001$ \\
UIS & 0.3182 & 0.1489 \\
Lactation & 0.8964 & 0.6972 \\
Lactose & $<0.0001$ & 0.0006 \\
SCC & 0.0020 & $<0.0001$ \\
Protein & $<0.0001$ & $<0.0001$ \\
Urea & 0.0011 & 0.0037 \\
Fat & 0.0095 & 0.0001 \\
DIP & & 0.0402 \\
DIM & & $<0.0001$ \\
Milk & 0.0203 & 0.0300 \\
Lactose $\times$ UIS & $<0.0001$ & 0.6187 \\
SCC $\times$ UIS & 0.0922 & 0.9716 \\
Protein $\times$ UIS & 0.0301 & 0.3838 \\
Urea $\times$ UIS & 0.2324 & 0.3852 \\
Fat $\times$ UIS & & 0.0714 \\
DIP $\times$ UIS & & 0.4361 \\
DIM $\times$ UIS & & 0.8891 \\
Milk $\times$ UIS & 0.0302 \\
$\mathrm{n}$ & & 407 \\
$\mathrm{R}^{2}$ & 0.25 & 0.470 \\
\hline
\end{tabular}

${ }^{1} \mathrm{DIP}=$ days in pregnancy.

define milk quality, to identify animals or glands that produce low-quality milk, and to prevent that milk from entering the BTM. In the present study it was demonstrated that the AfiLab can perform real-time, online classification of milk on the cow level, according to predetermined standards. It is foreseen that the described system could sort milk into several streams, according to pre-set standards. Such a capability could enable sorting of milk according to use (i.e., for drinking or cheese-making, or for rejection as unfit for human consumption). In the present study, the ability of the AfiLab to perform the above task was demonstrated, and its output was statistically validated by calibration against laboratory testing procedures. It is believed

Table 8. The ANOVA significance levels ( $P$-values) of the main effect of the bacterial infection groups $(1,2,3$, or 4$)$ on rennet clotting time $(\mathrm{RCT})$ and curd firmness after $90 \mathrm{~min}(\mathrm{CF}-90 \text { values })^{1}$

\begin{tabular}{lcc}
\hline Source & $\begin{array}{c}P \text {-value } \\
(\mathrm{RCT})\end{array}$ & $\begin{array}{c}P \text {-value } \\
(\mathrm{CF}-90)\end{array}$ \\
\hline Infection bacterial group & 0.6792 & 0.0015 \\
Lactose & $<0.0001$ & 0.0030 \\
$\mathrm{SCC}$ & 0.0525 & 0.0530 \\
Protein & $<0.0001$ & 0.0047 \\
Urea & 0.2814 & 0.0780 \\
Fat & 0.0605 & 0.0558 \\
$\mathrm{n}$ & 414 & 407 \\
$\mathrm{R}^{2}$ & 0.31 & 0.533 \\
\hline${ }^{1}$ Bacterial infection groups were no bacterial infection, CNS infection, \\
Streptococcus dysgalactiae infection, or Escherichia coli infection.
\end{tabular}

Table 9. Online validation statistics for determination of clotting parameters in raw milk by the AfiLab

\begin{tabular}{lcll}
\hline Parameter & SECEV & $\mathrm{CV}_{\mathrm{r}}$ & $\begin{array}{l}\mathrm{CV} \\
(\%)\end{array}$ \\
\hline CF-90 & 1.309 & 91.3 & 12.2 \\
RCT & 286 & 63.2 & 25.2 \\
\hline
\end{tabular}

${ }^{1} \mathrm{SECEV}=$ standard error of cross-validation; $\mathrm{CV}_{\mathrm{r}}=$ cross-validation correlation coefficient; $\mathrm{CV}=(\mathrm{SECEV} /$ mean value $) \times 100 ; \mathrm{CF}-90=$ curd firmness after $90 \mathrm{~min}$; RCT $=$ rennet clotting time. AfiLab from S.A.E. Afikim, Afikim, Israel.

that implementation of such equipment in milking parlors would enable milk producers, in cooperation with the dairy industry, to channel milk according to predetermined standards set by the operators, and thus, to increase both parties' benefits from the use of that milk.

The foreseen advantages of online milk sorting according to the predetermined values could benefit scientists, farmers, and the milk industry. Using the AfiLab online during various experiments performed in a dairy herd enables collection of data that was unavailable previous to its installation. During feeding experiments, besides collecting data on the changes of milk composition, scientists will also have a unique signal to draw their attention to the milk quality, because some of it is related to distinct changes in lactose content and clotting parameters. Recently, it was shown that intramammary infection and late lactation cause a decrease in lactose level and impaired clotting parameters. It was noted that when lactose level is decreased to approximately $4 \%$, milk does not coagulate at all (Leitner

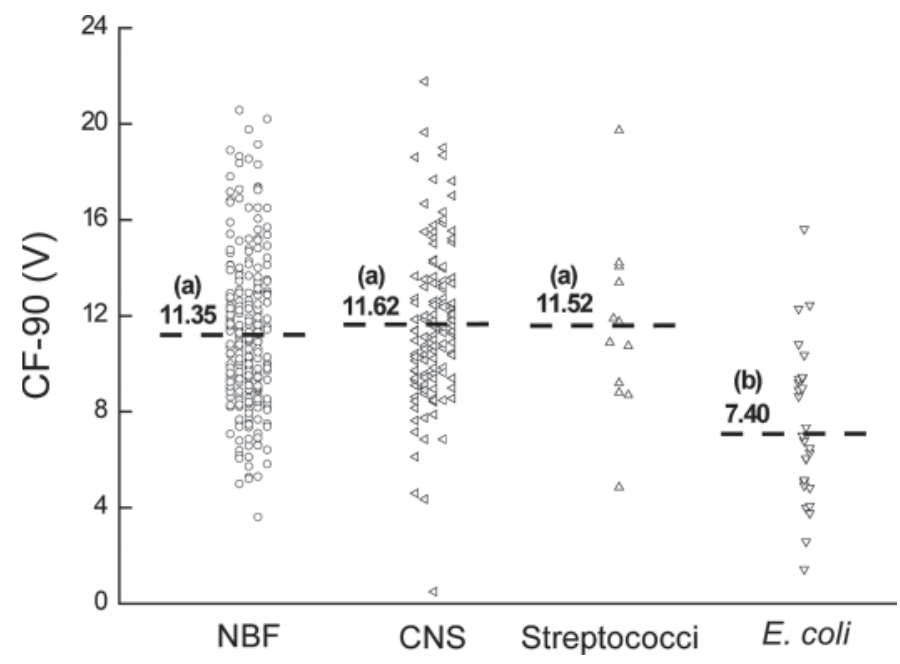

Figure 5. Distribution of curd firmness after $90 \mathrm{~min}$ (CF-90) in the 4 udder infection bacteria groups [no bacterial finding (NBF), 258; CNS, 124; streptococci, 12; Escherichia coli, 29]. ${ }^{\text {a,b }}$ Values marked with different letters in parentheses differ significantly $(P<0.05)$. 

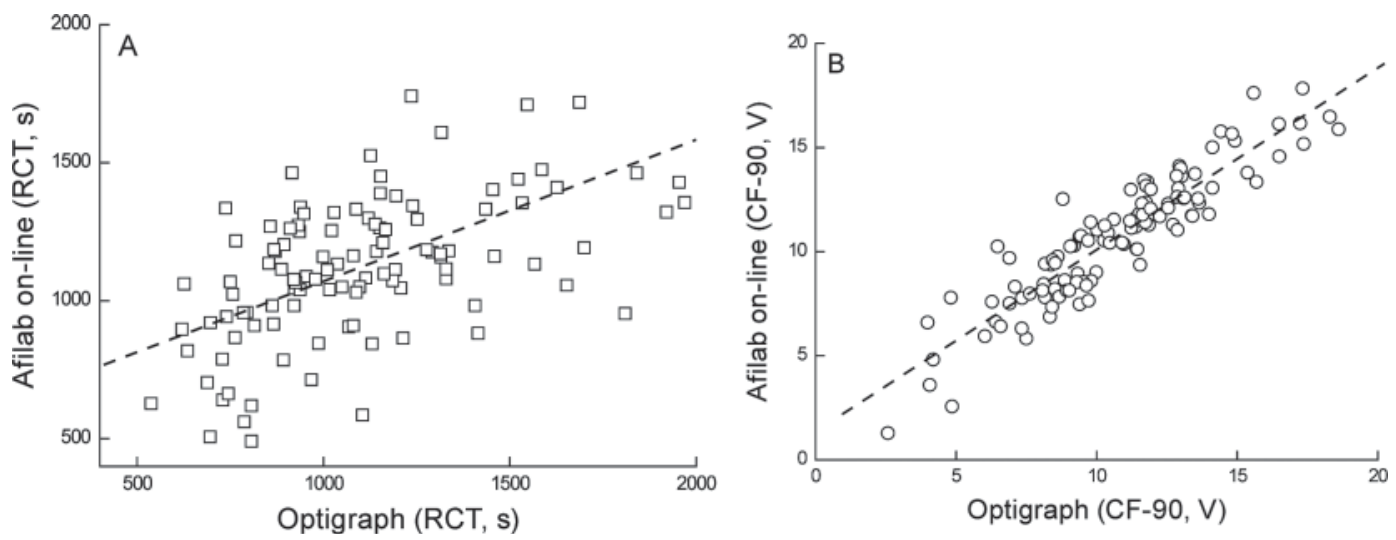

Figure 6. Correlation between AfiLab-predicted values (S.A.E. Afikim, Afikim, Israel) for rennet clotting time (RCT; A) and curd firmness after 90 min (CF-90; B) and values measured with the Optigraph (Ysebaert, Frepillon, France).

et al., 2011). Farmers might use this device to obtain an online alarm for cows that have a certain problem in milk quality, which might call for further scrutiny, especially for a possible unnoted subclinical infection. Industrial dairies might be the ultimate candidates to impose the implementation of such a device, owing to the possible increase in cheese yield of the collected milk and thus, better economic return.

\section{REFERENCES}

Auldist, M. J., S. Coats, B. J. Sutherland, J. J. Mayes, and G. H McDowell. 1996. Effects of somatic cell count and stage of lactation on raw milk composition and the yield and quality of cheddar cheese. J. Dairy Res. 63:269-280.

Auldist, M. J., and I. B. Hubble. 1998. Effects of mastitis on raw milk and dairy products. Aust. J. Dairy Technol. 53:28-36.

Barbano, D. M., R. R. Rasmussen, and J. M. Lynch. 1991. Influence of milk somatic cell count and milk age on cheese yield. J. Dairy Sci. 74:369-388.

De Marchi, M., C. Fagan, C. P. O'Donnell, A. Cecchinato, R. Dal Zotto, M. Cassandro, M. Penasa, and G. Bittante. 2009. Prediction of coagulation properties, titratable acidity and $\mathrm{pH}$ of bovine milk using mid-infrared spectroscopy. J. Dairy Sci. 92:423-432.

Jouan-Rimbaud, D., D.-L. Massart, R. Leardi, and O. E. De Noord. 1995. Genetic algorithm as a tool for wavelength selection in multivariate calibration. Anal. Chem. 67:4295-4301.

Katz, G., A. Arazi, N. Pinsky, I. Halachmi, Z. Schmilovitz, E. Aizinbud, and E. Maltz. 2007. Current and near term technologies for automated recording of animal data for precision dairy farming. J. Anim. Sci. 85(Suppl. 1):377.

Klei, L., J. Yun, A. Sapru, J. Lynch, D. M. Barbano, P. Sears, and D. Galton. 1998. Effects of milk somatic cell count on cottage cheese yield and quality. J. Dairy Sci. 81:1205-1213.

Leitner, G., O. Krifucks, U. Merin, Y. Lavi, and N. Silanikove. 2006. Interactions between bacteria type, proteolysis of casein and physico-chemical properties of bovine milk. Int. Dairy J. 16:648-654.

Leitner, G., U. Merin, and N. Silanikove. 2011. Effects of glandular bacterial infection and stage of lactation on milk clotting parameters: Comparison among cows, goats and sheep. Int. Dairy J. 21:279-285. doi:10.1016/j.idairyj.2010.11.013.

Leitner, G., N. Silanikove, S. Jacobi, L. Weisblit, S. Bernstein, and U. Merin. 2008. The influence of storage on the farm and in dairy silos on milk quality for cheese production. Int. Dairy J. 18:109-113.

McLaughlin, F. 2006. A brief comparison of United States and European Union standards for fluid dairy production. Michigan State
University, East Lansing. Accessed October 2010. http://www. iflr.msu.edu/BookStudentPapers_files/A_Brief_Comparison_ of_United_States_and_European_Union_Standards_for_Fluid_ Dairy_Products.pdf.

Merin, U., G. Fleminger, J. Komanovsky, N. Silanikove, S. Bernstein and G. Leitner. 2008. Subclinical udder infection with Streptococcus dysgalactiae impairs milk coagulation, properties: The emerging role of proteose-petones. Dairy Sci. Technol. 88:407-419.

Munro, G. L., P. A. Grieve, and B. J. Kitchen. 1984. Effects of mastitis on milk yield, milk composition, processing properties and yield and quality of milk products. Aust. J. Dairy Technol. 39:7-16.

Oliver, S. P., R. N. Gonzalez, J. S. Hogan, B. M. Jayarao, and W. E. Owens. 2004. Microbiological Procedures for the Diagnosis of Bovine Udder Infection and Determination of Milk Quality. 4th ed. National Mastitis Council, Verona, WI.

Politis, I., and K. F. Ng-Kwai-Hang. 1988. Association between somatic cell counts of milk and cheese yielding capacity. J. Dairy Sci. $71: 1720-1727$.

Rogers, S. A., and G. E. Mitchell. 1994. The relationship between somatic cell count, composition and manufacturing properties of bulk milk. 6. Cheddar cheese and skim-milk yogurt. Aust. J. Dairy Technol. 49:70-74.

SAS Institute. 2000. JMP User's Guide. SAS Institute, Inc., Cary, NC. Schmilovitch, Z., I. Shmuelevich, A. Notea, and E. Maltz. 2000. Near infrared spectrometry of milk in its heterogeneous state. Comput. Electron. Agric. 29:195-207.

Soyeurt, H., I. Misztal, and N. Gengler. 2010. Genetic variability of milk components based on mid-infrared spectral data. J. Dairy Sci. 93:1722-1728.

Tsenkova, R., S. Atanassova, H. Morita, K. Ikuta, K. Toyoda, I. K. Iordanova, and E. Hakogi. 2006. Near infrared spectra of cow's milk for milk quality evaluation: Disease diagnosis and pathogen identification. J. Near Infrared Spectrosc. 14:363-370.

Tsenkova, R., S. Atanassova, K. Toyoda, Y. Ozaki, K. Itoh, and T. Fearn. 1999. Near-infrared spectroscopy for dairy management: Measurement of unhomogenized milk composition. J. Dairy Sci. 82:2344-2351.

Urech, E., Z. Puhan, and M. S. Schällibaum. 1999. Changes in milk protein fraction as affected by subclinical mastitis. J. Dairy Sci. 82:2402-2411.

USFDA. 2007. Grade "A" pasteurized milk ordinance. US Department of Health and Human Services, Public Health Service, Food and Drug Administration, Washington, DC.

Zeiri, Y., E. Fattal, and R. Kosloff. 1995. Application of genetic algorithm to the calculation of bound states and local density approximations. J. Chem. Phys. 102:1859-1862. 